\title{
CREATING CONTEMPORARY PICTURE SHORT STORIES USING INTERTEXTUAL HEROES \& PLOT SUBVERSION: AN EMPIRICAL RESEARCH
}

\author{
Christina Kalaitzi \\ Dr., Faculty of Education, School of Early Childhood Education, Aristotle University of Thessaloniki \\ (Greece)
}

\begin{abstract}
It is a fact nowadays that the child's ability to acknowledge specific narrative structures has become one of the main objectives in the field of children's literature and its teaching approach. Although there is plenty of research showing that preschoolers are able to comprehend and generate both verbal and pictorial narrative structures, there is no recent study concerning the way in which specific narrative elements can be used in combination to produce a particular literary type. Taking this fact into account, the particular research aims to assess preschoolers' ability of creating contemporary picture short stories using two dominant narrative elements. Therefore, the evaluation of the extent to which the 'intertextual hero' and the 'plot subversion' elements can be used in their narrative speech, is explored. For the purposes of this empirical research, a teaching intervention was conducted with a sample composed of preschoolers from two public Greek Kindergartens, aiming at the creation of contemporary picture short stories containing elements of intertextual heroes and plot subversions. More specifically, the preschoolers' performance of using the aforementioned narrative elements in their narrative speech is evaluated via context analysis. The results prove that the teaching approach of these specific narrative elements led to their use in the preschoolers' narrative speech in order to generate narratives of the picture short story type. The particular research discusses the way in which teaching approaches centered on contemporary picture short story's narrative elements could develop the narrative skill in early childhood.
\end{abstract}

Keywords: Picture short story, intertextual hero, plot subversion, teaching intervention, early childhood.

\section{The use of intertextual hero and plot subversion by preschoolers on their narrative speech}

During early childhood, the narrative skill plays a fundamental role in the development of self-esteem and at the same time sets the foundations for narrative comprehension and literacy skills (Whitehead, 2010). The development of narrative skill leads children's informal, verbal interactions to formally structured written communication patterns (Gamble \& Yates, 2008). According to Melrose's critical review (2012) of the development of preschoolers' writing skill, it appears that reading picture books could be likened to the creation or writing of a story. In Cairney (1992) and Lancia (1997) researches on the interdependence of illustrated stories, the findings revealed that the narrative speech of preschool and primary stage was influenced by the texts they already knew. Both researchers observed that students made reference to other texts in their own oral and written narratives in the following ways: by copying or reproducing a particular literary genre, by using the heroes or character archetypes, by including identifiable contents without copying the plot completely, by copying the plot, by overturning the events, by copying plot and content together, by transforming descriptive content into a narrative, and by creating a new narrative using other pictorial narratives.

\section{Research design}

\subsection{Objective}

The reason why this research has limited itself to exploring the understanding and use of the intertextual hero and the plot subversion is because the use of these specific narrative elements develops the ability to decode and interpret pre-existing knowledge, such as the perception of the chronological order of plot events, the archetypal heroes and fairy tale patterns (Pantaleo, 2006; Lancia, 1997; Cairney, 1992). Although field studies have shown that each of the above narrative elements can be used by preschool 
children, there is limited research on how they can be used combined in the production of narrative speech based on the theories of creativity (Dresang, 1999). In order to prove the above hypothesis, it was attempted to explore the extent to which the narrative elements of intertextual hero and plot subversion can be used in combination by preschool children in order to create contemporary picture short stories.

\subsection{Sample}

Two public kindergartens were selected for sampling on the basis of social equivalence and cultural parity (Bloom \& Quint, 1999). Two groups of preschoolers (one group per kindergarten) participated in the research with a total number of thirty four preschoolers. The sample formed of preschoolers of typical development, between the age of 5 and 6,5 years old, since at this age their narrative skill is differentiated significantly and is developed radically into distinctive developmental stages enabling the comprehension and generation of specific structural and morphological narrative elements (John et al., 2003; McCabe \& Rollins, 1994; Applebee, 1973).

\subsection{Teaching intervention}

The particular empirical research included the observation of the population sample during their participation in a teaching intervention conducted within a six month period (Allington, 2001). Before the implementation of the intervention, preschoolers were asked to produce short stories based on fairytale pictures by introducing characters from other fairytales and making any necessary changes to the plot. The intervention consisted of specially designed and adapted activities, based on the objectives of the national curriculum regarding the learning area of language, so that their learning outcomes could prove the hypothesis of the present research. The performance in the activities of the intervention was evaluated by the researcher through context analysis of the preschoolers' narrative speech (Huckin, 2004). The design and implementation of this intervention aimed at the assessment of the comprehension level and use of specific narrative elements in preschoolers' narrative speech (Silva et al., 2014; Landry et al., 2006; Doyle \& Bramwell, 2006), in particular, the two elements which were evaluated were the intertextual hero (introduction of a new fairytale character in a specific role) and the plot subversion (reversal of the sequence of events). The activities of the teaching intervention were categorized in two program phases. Each phase of the intervention was aimed at the comprehension and use of a specific indicator. Each indicator (I) was evaluated in regards to the degree of comprehension (C) and use (U) through four specially designed activities (two activities aimed at comprehension and two activities aimed at use), which led at the specific learning outcomes, as described below in Figures $1 \& 2$. Each activity was repeated as many times as needed in order for every preschooler to produce narrative speech.

Figure 1. Teaching Intervention objectives and activities aiming at comprehension and use of the intertextual hero indicator (II).

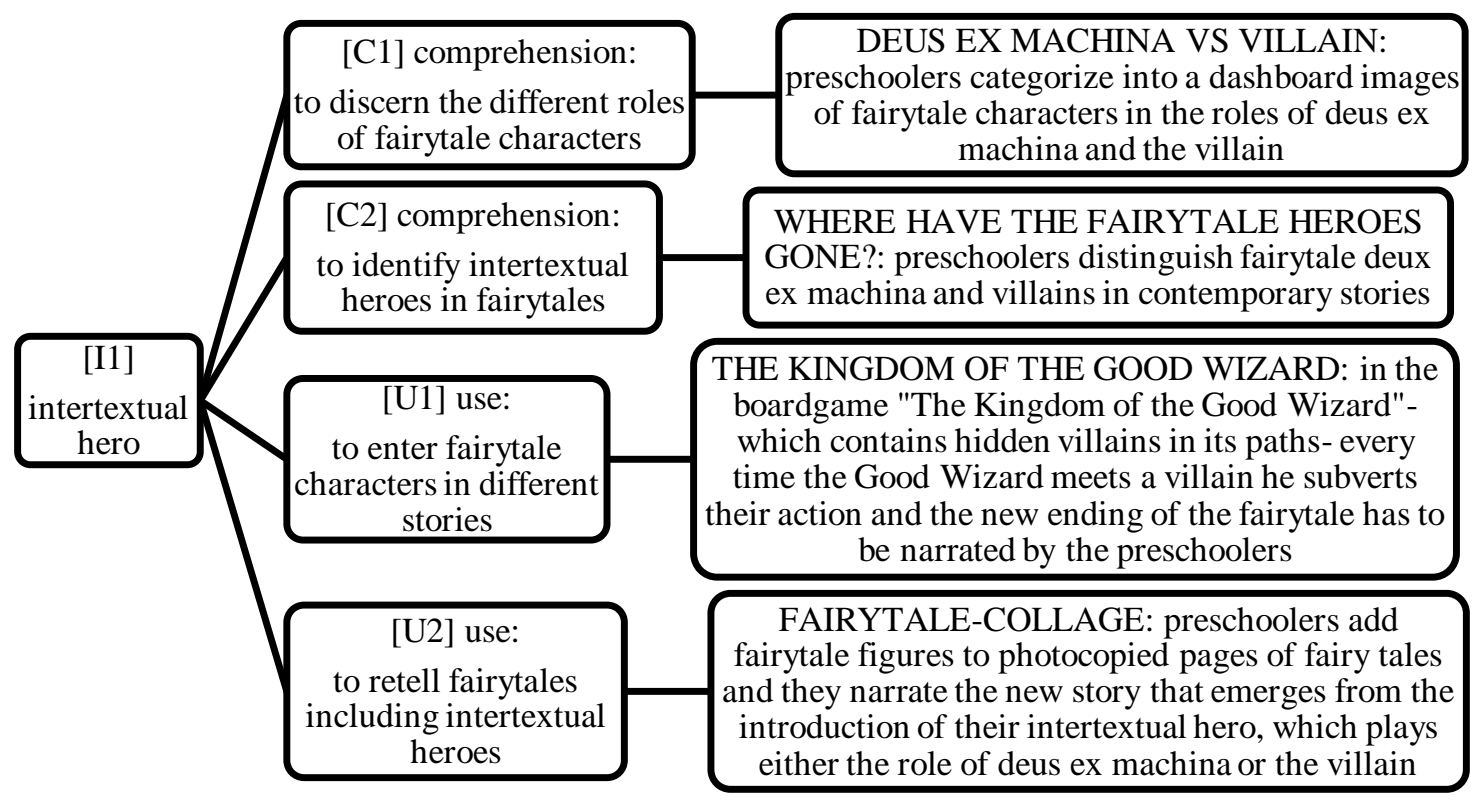


Figure 2. Teaching Intervention objectives and activities aiming at comprehension and use of the plot subversion indicator (I2).

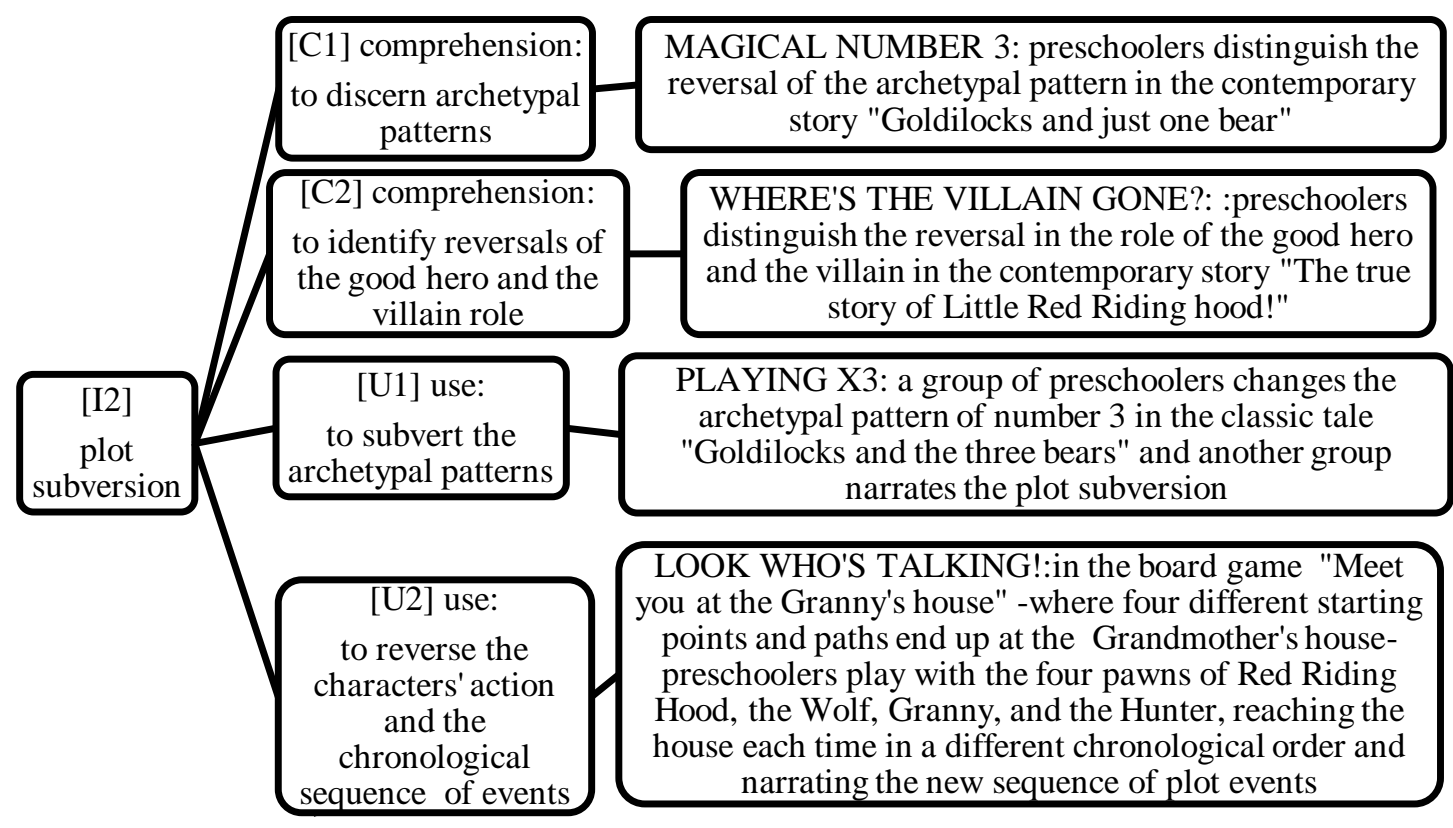

\section{Discussion of findings}

\subsection{Context analysis of preschoolers' narrative speech}

For the present study, the context analysis of preschoolers' narrative speech produced during the intervention was chosen, as this qualitative approach treats data as representations of text, image and expression created to be interpreted by the researcher's personal judgment. It is a methodology which can be used to identify, quantitate and analyze specific words and phrases that can be observed in a text, aiming to discern certain subject or rhetorical patterns embodied (Huckin, 2004). The context analysis of narrative speech at the primary stage, before the implementation of the intervention, showed that preschoolers' short stories included intertextual heroes without any discreet role, whose introduction didn't cause any alteration to the plot of events. In fact, preschoolers had just retold the fairytale from where the picture had been extracted using the basic narrative structure. On the contrary, the evaluation of the narratives produced by the preschoolers during the intervention confirmed the research hypothesis as the elements of the intertextual hero and plot subversion were detected in the texts. In particular, by understanding the possibility of introducing a hero to more than one story, preschoolers introduced characters from classical fairytales, contemporary stories and films and retold the earlier texts by intervening in certain parts of the plot and by subverting the sequence of events based on the profile of the new intertextual character (Transcription 1).

\section{Transcription 1. Introducing the intertextual hero.}

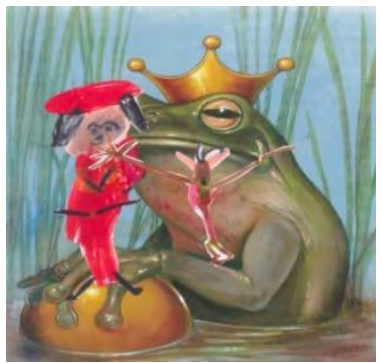

"Once upon a time there was a princess who was playing every day with her golden ball. One day she dropped the golden ball into the well and a frog brought it back to her but before the frog asked for his favor suddenly Lord Duloc came and grabbed the ball from the princess. But the Mother Goat who was nearby came to help. She bit Lord Duloc and he gave the ball back to the frog. Now the frog can ask from the princess to take him with her in the castle as a favor. But the princess didn't want him and she pushed him against the wall and his frog skin fell off and he became a king. The princess and the Frog King got married and they lived happily ever after"

In their produced narratives it is clearly showed that the role they gave to each intertextual character (deus ex machina or villain) was related to the reversal of the plot. Furthermore, by changing the archetypal patterns, as well as by overturning the linear sequence of events of fairy tales, the preschoolers produced contemporary versions of two classic fairy tales (Transcription 2). In their meta-narratives of "Goldilocks and the Three Bears", they distinguished and changed the fairytale pattern which they illustrated in groups embodying all of its new versions and depicting every single subversion in the character's action. 


\section{Transcription 2. Subverting the archetypal pattern.}

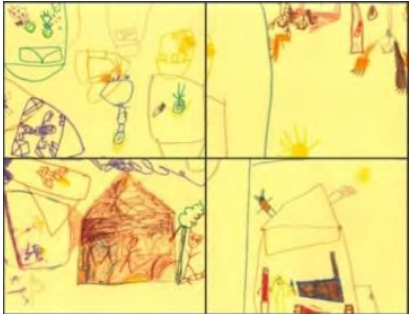

"...In the Bears house Goldilocks decided to play with the colors because she liked painting a lot. She painted the floor of the three Bears' house, her shoes and her face. When the three Bears returned to their house they slipped into the water colors that Goldilocks had forgotten to pick up from the floor. And then because Goldilocks left footprints all over the place with her colored shoes the Bears found her hiding. And when the tree Bears saw Goldilocks' painted face they got scare and they run away from their little house so Goldilocks stayed there forever"

In addition, through the board game LOOK WHO'S TALKING! preschoolers used the first person narrative to overturn the chronological order of events of the "The Little Red Riding Hood" classic fairy tale (Transcription 3).

Transcription 3. Overturning the sequence of events.

"I am the Granny and I reached my house and there was nobody inside and I started knitting" / "when me the Hunter reached the Granny's house I found her knitting so I went to hunt something for the Granny to cook it" / "when I the Red Riding Hood got in the Granny's house I found Granny knitting and I saw the Hunter hunting near the house to cook and eat. I sat down to watch TV"/ "when I the Wolf went to the Granny's house I saw Granny, Red Riding Hood and the Hunter inside. Granny was knitting, Red Riding Hood was watching TV and the Hunter had brought something for lunch and he was helping Granny with the cooking. I ate Red Riding Hood first and then I ate Granny and the Hunter together"

The design of the teaching approach of these specific narrative elements took into consideration the developmental stages of narrative speech through preschool age (Peterson \& McCabe, 2013; Applebee, 1973). It was the pre-existing knowledge that enabled preschoolers to categorize the fairy tale characters into the roles of deus ex machina and the villain in order to introduce them in different stories, intervening in the plot. After being familiar with the plot changes caused by the introduction of the intertextual hero, preschoolers attempted to subvert all the stages of a story, a skill which, according to Cairney (1992) and Lancia (1997) ) presupposes the decoding and interpretation of the pre-existing knowledge, such as the perception of the chronological order of plot events, as well as the recognition of the archetypal patterns. After the implementation of the intervention, preschoolers were asked once again to produce short stories based on fairytale pictures. At this last stage, preschoolers produced short stories introducing intertextual characters in a discrete role (either the one of deus ex machine or the villain) and by subverting the sequence of plot events. What is worth mentioning is that preschoolers took the initiative to illustrate their short stories in order to depict the intertextual heroes and the new chronological order of events in the picture as well (Transcription 4).

Transcription 4. A contemporary picture short story.

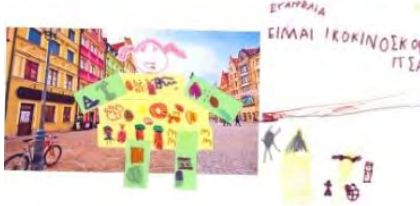

"Once upon a time there was Red Riding Hood. She had moved to a big city where there were a lot of colorful houses. Every house had a different color but they all looked like each other. One day Red Riding Hood went to her Granny's house to bring her some soup. But she was lost in the big city and she couldn't find her way to the Granny's house because all houses look like each other. Then Pluto came to help her. He sniffed their way to the Granny's house but he also sniffed the Big Bad Wolf

who was also inside the house. Pluto barked very loud and the Wolf got scared and he ran away without hurting the Granny. Red Riding Hood adopted Pluto to be her guide into the big city and she never lost her way to the Granny's house since then and they lived all together happily ever after in the colorful city"

In conclusion, the teaching intervention has produced measurable results which assess the development of preschoolers" narrative speech through the context analysis of their narratives produced during and after the implementation of the activities. The comparison between the primary and the latter stage of the research show that the preschoolers narratives were enriched in the extent of combining particular narrative elements and producing contemporary picture short stories using intertextual heroes \& plot subversion. 


\subsection{Limitations and future extension}

Given that the teaching intervention was implemented for the purposes of the present research at preschool stage, a multi-level approach is recommended for future use in order to achieve a holistic evaluation of reliability. Specifically, apart from the evaluation of performance at preschool age (level 1), the exploration of teacher's experience and attitude towards the effectiveness of the intervention could be considered in a second level (level 2), whilst in a third level (level 3) demographics of regions where the Kindergartens located can be included. With that multilevel analysis of nested data, the different levels (preschooler, teacher, kindergarten) will provide a more complete view due to multiple dimensions and criteria (Frenzel et al., 2007). Furthermore the consecutive implementation of the intervention in older stages could lead to assumptions regarding the development of narrative speech in regards to the use of specific narrative elements. In conclusion, it could be supported that the present research sets the grounds for discussion regarding the enhancement and development of practices aiming at the evaluation of narrative skill at preschool age.

\section{References}

Allington, R. (2001). What really matters for struggling readers: designing research-based programs. New York: Addison-Wesley Publishers Inc.

Applebee, A. N. (1973). The spectator role: theoretical and developmental studies of ideas about and responses to literature with special reference to four age levels. London: London University Press.

Bloom, H. S., \& Quint, J. (1999). .Assessing program impacts and implementation. U.S: Department of Education.

Cairney, T. (1992). Fostering and building students' intertextual histories. Language arts, 69(7), 502-507.

Doyle, B. G., \& Bramwell, W. (2006). Promoting emergent literacy and social-emotional learning through dialogic reading. The reading teacher, 59(6), 554-564.

Dresang, E. (1999). Radical change: books for youth in a digital age. New York: The H.W. Wilson Company.

Frenzel, A. C, Pekrun, R., \& Goetz, T. (2007). Perceived learning environment and students' emotional experiences: a multilevel analysis of mathematics classrooms. Learning and instruction, 17 (5), 478-493.

Gamble, N., \& Yates, S. (2008). Exploring children's literature: teaching the language and reading of fiction (2nd ed.). London: Sage.

Huckin, T. (2004). What writing does and how it does it: an introduction to analyzing texts. New Jersey: Lawrence Erlbaum Associates.

John, S. F., Lui, M., \& Tannock, R. (2003). Children's story retelling and comprehension using a new narrative resource. Canadian journal of school psychology, 18(1-2), 91-113.

Lancia, P. (1997). Literary borrowing: the effects of literature on children's writing. The reading teacher, 50(6), 470-475.

Landry, S. H, Swank, P. R, Smith, K. E, Assel, M. A., \& Gunnewig, S. B. (2006). Enhancing early literacy skills for preschool children. Journal of learning disabilities, 39(4), 306-324.

McCabe, A., \& Rollins, P. R. (1994). Assessment of preschool narrative skills. American journal of speech-language pathology, 3(1), 45-56.

Melrose, A. (2012). Monsters under the bed. Critically investigating early years writing. London \& New York: Routledge.

Pantaleo, S. (2006). Readers and writers as intertexts: exploring the intertextualities in student writing. Australian journal of language and literacy, 29 (2), 163-181.

Peterson, C., \& McCabe, A. (2013). Developmental psycholinguistics. Three ways of looking at a child's narrative. New York: Plenum Press.

Silva, M., Strassser, K., \& Cain. K. (2014). Early narrative skills in Chilean preschool: questions scaffold the production of coherent narratives. Early childhood research quarterly, 29(2), 205-213.

Whitehead, M. (2010). Language and literacy in the early years 0-7 (4th ed.). Los Angeles, London, New Delhi, Singapore \& Washington DC: Sage. 